\title{
The Impact of Peer Pressure to Disregard Parental Authority on Academic Achievement of Secondary Schools Students
}

\author{
Odu, Emmanuel N. \\ Institute of Public Policy and Administration (IPPA), University of Calabar, Calabar-Nigeria \\ Anoh, Janet M. \\ Department of Curriculum and Teaching, Faculty of Education, University of Calabar, Calabar-Nigeria
}

\begin{abstract}
This study investigated the impact of peer pressure to disregard parental authority on academic achievement of secondary school students. Two hypotheses were tested in this study. Relevant literature were consulted to support the study. The variant of research design that was adopted in this study is correlation survey design. Survey design involves obtaining data from a sample (survey) of the population. The study is carried out in Cross River State, Nigeria. Sample size of 400 was used. Multistage sampling procedure was adopted. A sampling technique combining simple and stratified random sampling was adopted for the purpose of this study. Stratification was done based on the educational zones in the state. In each zone, 4 Local government Areas were sampled using the simple random sampling method. In each local government Area, thirty-three (33) persons will be sampled by simple random sampling method. Questionnaire is used as instrument for data collection. Correlation coefficient is used to analyse data for the purpose of the study. Findings of the study include among others that Peer Pressure to overrule parental control/authority does significantly affect academic achievement among secondary school student in Cross River State, Nigeria. Based on the findings of this study, recommendations were made which include that a child should be trained and taught to appreciate parental authority. If necessary, strict disciplinary actions should be used by parents in an effort to carry this out.
\end{abstract}

DOI: $10.7176 / \mathrm{JEP} / 10-35-10$

Publication date: December $31^{\text {st }} 2019$

\section{Introduction}

Academic achievement is a measure of the effectiveness of the school system. It signifies the learning outcomes of the child. It is the degree by which a child has mastered what he has been taught in the school (Pandey 2008). It is the standard established against which the society judge the education system.A standard based education system promotes equity by establishing a baseline of knowledge and skills that all students, regardless of their background, should master as part of their education. It is generally accepted that academic performance is the way to measure the level of mastery of the students of the subject matter(s) they have been exposed to. Measuring academic achievement therefore provide the key information about students mastery of such standards. Academic achievement is therefore the current level of a student learning.

Academic achievement for all students is one of the key goals of the school's system, and mastery of set standard should provide students with useful skills for fulfilling a productive life. However, several factors may be responsible for the academic's achievement of a child/student. A child does not grow or develop all alone by himself. There are some influences exerted on him by his environment. This environment includes the family, peers' pressure, neighbourhood and school learning environment. Parent and family are also important in the socialization/development of their children/ward. Jaiswal and Choudhuri (2017) reported that parental involvement in education of their children is a key factor in their academic success as well as their total function.

Most formal education processes occur in a group setting. Students exist in their numbers - ina group setting. In the group setting, the group impact and influence on its members could be so strong with positive or negative outcome depending on the character of the group and/or the individual character of each person. In such a whole group, there are usually subgroups. In the schools setting, these sub groups could be referred to as peer groups.

Peer group is defined as a small group of the same aged persons; fairly close friends, sharing the same activities (Zaki, Thabet \& Hassan, 2014). The oxford Advance Learners Dictionary (2016) defined peer group as a group of people of the same age or social status. The peer group is the first social group outside the home in which the child attempts to gain acceptance and recognition. This means that it is a small group of similarly aged; fairly close friends, sharing the same activities. Given that adolescents spend twice as much time with peers as with parents or other adults, the influence or pressure of peers on their lives (and by implication, their academic achievement) can only be imagined.In general, peer groups have two to twelve members, with an average of five or six members. In a school setting each student usually belongs to one or the other except the isolates or rejects. Zaki, Thabet and Hassan (2014) explained that peer pressure could thus be defined as the direct influence on adolescents by peers, which is manifested in terms of changing their attitudes, values or behaviours. It could also be said to be the strong influence of a group, especially of children, on members of that group to behave as everyone 
else does. The individuals feels the pressure to behave in a certain way because his/her friends or people in her group expect it. It is a feeling that one must do the same things as other people of one's age and social group in order to be liked or respected by them.

The expectations and influence of the group on its members could be referred to as peer pressure. Peer pressure could be positive or negative. Peer pressure could be said to be positive when it has positive identified impact on teenagers. It is positive when it introduces positive hobbies and interest, increase self confidence, reinforces positive habits and attitudes and brings about a sense of belonging and support. A positive scenario of peer pressure is observed by Teens (2013) who explained that peer pressure encourages students' motivation and high self esteem. Also, students could participate in groups to thrive in the classroom. In the words of Zaki, Thabet and Hassan (2014), student peer groups can be motivated by working together. The interaction among peers is normal and essential part of the learning process that influences the lifelong learning habits of students. Students may learn better when they are in company of other strong students. On the other hand, peer pressure could be said to be negative if it leads to disregard to parental (or other authorities), teen depression, high stress levels, negative behaviour issues and poor decision making, taking alcohol, smoking or taking drugs and distractions from school work.

\section{Statement of the Problem}

Disregard to parental (or other) authorities, violent behaviour, lateness to school, truancy, inability to complete home work are common place among adolescence who are secondary schools students. These traits are generally believed to be negative and could be negatively impactful to a child's development and achievement. These negative impacts could play out in the child's academics as well as other areas of life. With respect to Cross River State, Nigeria, the state is still regarded as one of the educationally less privileged state in the federation. Could these vicious behaviours by secondary schools' student be a contributor to poor performance in Cross River State secondary schools? The secondary school student in Cross River remains under achieving in comparison to their counterparts in other parts of Nigeria. This low attainment of the goals in secondary school system of Cross River State is evident in poor academic achievement in external examinations such as WAEC and NECO.

The adolescents appear usually vulnerable to peer influence. Consequently, they appear easily lured into many social vices such as alcoholism, drugs addiction, rape, gangsterism, cultism, robbery, among others by members of their peer group (Berhane, 2012). These vices appear to completely distract their attention from studies hence the zeal to excel may be diminished resulting in poor academic achievement.It is against this background that this study asks, what is the predictive power of peer pressure to disregard parental authority on the academic achievement of secondary school students in Cross River State?

\section{Objective of the study}

The specific objectives of this study are to:

1. Investigate the extent to which peer pressure to disregard parental authority predict academic achievement of secondary schools students

2. Investigate the extent to which peer pressure to engage in alcohol/drugs predict academic achievement of secondary schools students

\section{Research hypothesis}

The following hypotheses to be tested in this study are hereby stated in null (Ho) form:

1. Peer Pressure to overrule parental control/authority does not significantly predict academic achievement among secondary school student in Cross River State, Nigeria

2. Peer Pressure to engage in hard drugs does not significantly predict academic achievement among secondary school student in Cross River State, Nigeria

\section{Literature Review \\ Concept of Peer Pressure}

A peer can be anyone you look up to in behavior or someone who you would think is equal to your age or ability. On the other hand, the term "pressure" implies the process that influence people to do something that they might not otherwise choose to do. Peer pressure is defined as small group of similar aged; fairly closed friends, sharing the same activities. According to Hartney, (2011) peer pressure refers to the influences that peers can have on each other. Peer pressure is emotional or mental forces from people belonging to the same social group (such as age, grade or status) to act or behave in a manner similar to themselves (Weinfied, 2010) Jones, (2010) defined peer pressure as the ability of people from the same social rank or age to influence another of same age bracket to do things or behave in ways they naturally would not. Peer pressure is usually associated with teens although its influence is not confined to teenagers alone.

Peer pressure is commonly associated with episodes of adolescent risk taking (such as delinquency, drug 
abuse, sexual behaviours), because these behaviour commonly occur in the company of peers. It can also have positive effects when adolescents are pressured by the peers toward positive behaviours, such as volunteering for charity or excelling in academics (Kellie, 2013). However, peers can also have a negative influence. They can encourage each other to skip classes, steal, cheat, use of drugs or alcohol, or become involve in other risky behaviours. Majority of adolescents with substance abuse problems appear to have begun using drugs or alcohol as a result of peer pressure. Negative peer pressure may be revealed in various ways like joining groups who drink alcohol, smoke cigarette and Indian hemp among others. It may also lead to the decision to have a boyfriend/girlfriend; Peer pressure might lead adolescents into loitering about in the streets, watching films and attending parties during school hours, taping as alternative to stealing which may eventually graduate into armed robbery. (Arief, 2011). In general, peer pressure has two to twelve members, with an average of five or six. Given the fact that formal education usually occurs in a group setting, peer group is potentially very important to a child education experience. The group impact and influence its members so that it pushes the group as a whole and its members. Peer effect, if positive, is an important component in determination of student outcomes (Cooley, 2010). A typical student learns from discussions with his peers affected by their personality and attitude towards learning. Peer groups can also be motivated by working together. It is well established that the quality of peers could affect a wide range of students outcomes from school performance (Jan, 2013).

A positive application of the peer group influence in education is peer-assisted learning that encourages students to take the responsibility for the learning process in terms of academic achievement and social development. A good peer group is helpful to attain better marks. If the peer group is academically bright, the student mights also work harder to achieve good grades in order to maintain the value. The peer group, if they have more interest in studies, can also compel the students to do more in personal effort and increase academic achievement to support a learning process (Nasreen and Nas, 2013).

\section{The Concept of Academic Achievement}

Academic Achievement of a child could be defined as the learning outcomes of the child. This includes the knowledge, skills and ideas, acquired and obtained through their course of study within and outside the classroom situation; it is the outcome of determination, hard work, of student in academic pursuit. Pandney, (2008) defined academic achievement as the performance of the pupils in the subjects they study in the school. This determinesthe pupils' status HI the class. This gives children an opportunity to develop their talents, improve their grades and prepare for future academic challenges.

Academic Achievement refers to a person's performance in a given academic area (eg reading or language arts mathematics, science and other areas of human Seaming, Academic Achievement relates to academic subjects a child studies in school and the skills the child is expected to master in each (Kathryn, 2010), Academic Achievement covers excellence in all academic discipline, in a class as well as extra-curricular activities. It includes excellence in sporting behaviour, it includes excellence in sporting behaviour, confidence, communication skills, and others. Steinberger (2005) posit that Academic Achievement encompasses students' ability and performance; it is multidimensional; it is intricately related to human growth and cognitive, emotional and social physical development; it reflects the whole child; it is not related to a single instance, but occurs across time and levels through a student's life in public school and into post-secondary years and working life. Academic Achievement refers to how well a student is accomplishing his tasks and studies.

Academic Achievement in school is evaluated in a number of ways. For regular gluing, students demonstrate their knowledge by taking written and oral tests, performing presentations, submission of homework and participating in class activities and discussion. Teachers evaluate achievement in the form of assignment, test and examination to describe how well a student has done. Poor academic achievement is a performance that is adjudged by the examiner arid some significant others as falling below an expected standard (Adesemowo, 2005). Izundu, (2005) pointed out that some environmental variables in a home iafhier.ce the learning capabilities of a child either positively or negatively and thus affect their academic achievements. Some of the variables include parental socioeconomic stains level of parental supervision of children, home location, and library facility among others. According to Uche (2010), parental and socio-economic status have some impact on academic achievement. Children of literate and high-income parents perform better in school than those from poor and uneducated parents. Children from, high socio economic homes eat balanced diet, enjoy good health and facilities that stimulates their intellectual activity and make them perform better academically than their counterparts who indulge in smoking cigarette, Indian hemp and other anti-social behaviours which may result to poor performance. He asserts that adolescent who come from homes regarded as having good or high socio-economic status may tend to do better than those who have poor homes. The study revealed that insufficient parental income: family type and lack of funding by government are factors influencing student's Academic Achievement. 


\section{Research Methodology \\ Research Design}

The variant of research design that will be adopted in this study is correlation survey design. Survey design involves obtaining data from a sample (survey) of the population. Thus survey is basically descriptive in nature. The essence is to help the researcher to synthesize, integrate and interpret data. It also helps not only to investigate phenomena in their neutral setting, but also to obtain accurate assessment of the characteristics of the whole population of people under study. According to Nworgu (1991), a correlational survey research is the type of study which seeks to establish what relationship exists between two or more variables. In this particular study, the predictor variable is peer pressure while the dependent variable is academic achievement of students in secondary schools in Cross River State. Nigeria.

\section{Area of study}

The study is carried out in Cross River State, Nigeria. There are 145 post-primary schools, a state college of education, A Federal college of education and a University of Technology in the state. Also, there is a Federal University-the University ofCalabar (UNICAL). The State is geographically bounded to the west by Ebonyi and Abia State, on the south west by Akwalbom State, on the East by Cameroon Republic and the North by Benue State. The state has three educational zones - North, south and central. The State capital territory is Calabar.

\section{Sampleand Sampling Techniques}

The sample will be 400 senior Secondary School Students, Taro Yamane formula is used to get the sample size. The formula is stated thus

$\mathrm{n}=\mathrm{N} /\left(1+\mathrm{Me}^{2}\right)$

Where $\mathrm{n}=$ sample size

$\mathrm{N}=$ population sixe

$\mathrm{E}=$ error of sampling or degree of error expected (usually $0.01,0.05$ )

Sampling size, $\mathrm{n}=80000 /(1+80000(.05) 2)$

Therefore for the purposes of this study, sample size of 400 will be used.Multistage sampling procedure will be adapted. A sampling technique combining simple and stratified random sampling will be adopted for the purpose of this study. The stratified random sampling technique is used in the study. Stratification was done based on the educational zones in the state. The three educational zones (which also form the three (3) geopolitical zones of the state) are used to constitute the strata for the study. In each zone, 4 Local government Areas will be sampled using the simple random sampling method. In each local government Area, thirty -three (33) persons will be sampled by simple random sampling method. In the local Government area (LGA), data will be obtained by administering questionnaire to student. Simple random sampling (otherwise known as "hat and draw") was used for the purpose of obtaining a non -biased observation from the population. This is to give every single member of the population equal chance (probability) of being selected for observation. Composing the sample from three (3) different strata that represented the geopolitical zones of the state makes the sample representative. Combining this with simple random sampling gives each member of the population equal and fair chance of being selected for the sample, thus making die sample a fair representation of the population.

\section{Instrument for data collection}

The instrument used for this study will be made of three (3) sections.

Section A will capture the personal bio-data (such as sex, education status, and occupational status) of the respondents. These data are referred to as socio demographic characteristics of the respondent. Section B of the instrument will be a Peer Pressure Inventory (PPI) which is developed after a thorough review of literature on peer pressure and academic achievement of students. The questionnaire was structured on a four - point rating scale. The inventory contains twenty - four (24) items about how much one goes along with his friends. The items on peer pressure have a rating scale of strongly agree, Agree, Disagree and Strongly Disagree. The statement in the inventory measures the two (2) situational variable representing two (2) hypothesis formulated in this study. The items in the inventory will be used for data analysis. The average score for each item will be computed to get the actual score on that item. These scores will be computed and used for data analysis. Section $\mathrm{C}$ of the instrument is the 2018 senior school certificate objectives Examination question paper in Economics. This will produce achievement scores for set of students that will be used for the study.

\section{Method of Data Analysis}

Correlation coefficient is used to analyse data for the purpose of the study. The correlation coefficient is a measure of how good a relationship exist between the two variables. Based on the results, inference will be made of each research question.

Correlation coefficient $\mathrm{r}=\left(\sum \mathrm{xy}-\left(\sum \mathrm{x} \sum \mathrm{y}\right) / \mathrm{n}\right) / \sqrt{ }\left[\left(\sum \mathrm{x}^{2}-\left(\sum \mathrm{x}\right)^{2} / \mathrm{n}\right)\left(\sum \mathrm{y}^{2}-\left(\sum \mathrm{y}^{2} / \mathrm{n}\right)\right]\right.$, where 
$\mathrm{X}=$ Observation on Variable $\mathrm{X}$,

$\mathrm{Y}=$ Observation on Variable $\mathrm{Y}$,

$\mathrm{n}=$ number of observations.

\section{Results}

Tests of hypotheses

Hypothesis One

$\mathrm{H}_{\mathrm{o}}$ : Peer Pressure to overrule parental control/authority does not significantly predict academic achievement among secondary school student in Cross River State, Nigeria

$\mathrm{H}_{\mathrm{i}}$ : Peer Pressure to overrule parental control/authority does significantly predict academic achievement among secondary school student in Cross River State, Nigeria

Table 1 shows that the correlation coefficient $R$ between peer pressure to disregard parental control and poor academic achievement is 0.74 (74 percent), and the P-value is 0.047 . Since P-value (0.047) is less than a (0.05), we do have enough to reject $\mathrm{H}_{0}$, which states that Peer Pressure to overrule parental control/authority does not significantly predict academic achievement among secondary school student in Cross River State, Nigeria. We therefore accept $\mathrm{H}_{1}$, and conclude that Peer Pressure to overrule parental control/authority does significantly affect academic achievement among secondary school student in Cross River State, Nigeria. Further test shows that $r$ (0.74) is greater than tabulated (critical) $\mathrm{R}_{0.05}(0.16)$, we therefore reject $\mathrm{H}_{\mathrm{o}}$ and accept $\mathrm{H}_{1}$.

\section{Hypothesis Two}

$\mathrm{H}_{\mathrm{o}}$ : Peer Pressure to engage in hard drugs does not significantly predict academic achievement among secondary school student in Cross River State, Nigeria

$\mathrm{H}_{\mathrm{i}}$ : Peer Pressure to engage in hard drugs does significantly predict academic achievement among secondary school student in Cross River State, Nigeria

Table 2 shows that the correlation coefficient $R$ between peer pressure to alcohol/hard drugs and poor academic achievement is 0.69 (69 percent), and the P-value is 0.047 . Since P-value (0.047) is less than a (0.05), we do have enough to reject $\mathrm{H}_{0}$, which states that Peer Pressure to engage in hard drugs does not significantly predict academic achievement among secondary school student in Cross River State, Nigeria. We therefore accept $\mathrm{H}_{1}$, and conclude that Peer Pressure to engage in hard drugs does significantly affect academic achievement among secondary school student in Cross River State, Nigeria. Further test shows that $\mathrm{r}(0.69)$ is greater than tabulated (critical) $\mathrm{R}_{0.05}$ (0.16), we therefore reject $\mathrm{H}_{\mathrm{o}}$ and accept $\mathrm{H}_{1}$.

Table 1:Correlation Analysis for Peer pressure to disregard parents and Academic performance

$\begin{array}{ll}\text { Peer pressure to } & \text { Poor academic } \\ \text { disregard parents } & \text { performance } \\ 1 & .74 \\ & .047 \\ 400 & 400 \\ .74 & 1 \\ .047 & \\ 400 & 400\end{array}$

Source: Field Work 2019

Peer Pressure to disregard parents

Poor academic performance

Decision rule: Reject null hy whether the correlation coefficient $(r)$ is significant at $\mathrm{P}=0.05$. If $\mathrm{r}<\mathrm{r}$-value at $\mathrm{P}=0.05$, fail to reject the null hypothesis and stop. Otherwise, reject null.

Peer pressure to

Pearson Correlation

$\mathrm{N}$

Pearson Correlation

Sig. (2-tailed)

$\mathrm{N}$ alcohol/drug addiction

Poor academic performance

Pearson Correlation

Peer Pressure to Sig.(2-tailed) 1

.69

.047

alcohol/drug addiction

Poor academic performance

N

Pearson Correlation Sig. (2-tailed)

$\mathrm{N}$
400

.69

.047

400
400

1

400

Source: Field Work 2019

Decision rule: Reject Null hypothesis if $\mathrm{p}$-value of correlation coefficient $<0.05$. Use statistical tables to check whether the correlation coefficient ( $r$ ) is significant at $\mathrm{P}=0.05$. If $\mathrm{r}<\mathrm{r}$-value at $\mathrm{p}=0.05$, fail to reject the null hypothesis and stop. Otherwise, reject null. 


\section{Discussion of Findings}

The findings of the first hypothesis show that there is significant relationship between peer pressure to overrule or disregard parental authority and poor academic performance among secondary school students in Cross River State, Nigeria. A high correlation coefficient of 0.74 ( 74 percent) was observed between peer pressure to overrule or disregard parental authority and poor academic performance among secondary school students in Cross River State, Nigeria. This indicates that the more secondary school students yield to pressure to disregard and overrule parental authority, the more they are likely to perform poorly in their academics. This could be explained thus: parents obviously want the best for their children, and will do their best for their children's best development. Most of the time, when adolescents challenge their parent's responsibility, they (the adolescents) are going against what is best for themselves. This often results in a negative outcome in several areas of life, the academic achievement are often not spared from these negative consequences, hence the resultant poor academic performance.

This could be said to be a classic case of negative peer pressure with the outcome coming negative also. Peer pressure to overrule and disregard parental control could be experienced by an adolescent who mixes with other students who engage is such unwholesome behavioural patterns. Such a group of youths/teenagers and anyone who is influenced by them may find it the norm to engage in disregard for parental authority. This is supported by Settenberg (2015) when he opined that youths may be influenced to do things that they you would not normally do if they are in a crowd of negative influence. The idea that "everyone else is doing it so why shouldn't 1?" can make otherwise sensible adolescents behave in strange ways. Such strange behaviour could manifest as disregard to parental authority.

The finding of this study on peer pressure to disregard parental authority is supported by Fuligni et. al. (2001) who noted that Extreme orientation toward peers, involving willingness to ignore parents' rules, schoolwork, and one's own skills for the sake of popularity, has been linked to greater problem behaviour in seventh, tenth, and twelfth grade and lower academic achievement in junior and senior secondary classes. Such extreme orientation toward negative influence is bound to have some effects on the character and development of such adolescents who are exposed to and influenced by them. The attendant negative outcomes turn out to be poor academic achievement as shown in the findings of this study.

The findings of the second hypothesis show that there is significant relationship between peer pressure to alcoholism/drug addiction and poor academic performance among secondary school students in Cross River State, Nigeria. A high correlation coefficient of 0.69 (69 percent) was observed between peer pressure to alcoholism/drug addiction and poor academic performance among secondary school students in Cross River State, Nigeria. This indicates that the more secondary school students yield to pressure to engage in alcoholism/drug addiction, the more they are likely to perform poorly in their academics. This could be explained thus: when adolescents start getting hooked to alcohol and hard drugs, getting hooked starts to take much of their time and attention. Most of the time, such adolescents get distracted from their rightful responsibilities such as their academics. Also, most of the time, alcoholism/drug addiction is followed by violence and other deviant behaviours. This often results in a negative outcome in several areas of life, the academic achievement are often not spared from these negative consequences, hence the resultant poor academic performance.

The finding of this study with regards to peer pressure to alcoholism/drug addiction is supported by Fuligni (2001). according to him, Peer pressure is commonly associated with episodes of adolescent risk taking (such as delinquency, drug abuse, sexual behaviours), because these behaviour commonly occur in the company of peers. Negative peer pressure may be revealed in various ways like joining groups who drink alcohol, smoke cigarette and Indian hemp among others. It may also lead to the decision to have a boyfriend/girlfriend; Peer pressure might lead adolescents into loitering about in the streets, watching films and attending parties during school hours, taping as alternative to stealing which may eventually graduate into armed robbery.

Fuligni (2001) also reported the evidence of homophily in antisocial behaviour, where the proportion of adolescent's friends who drink alcohol, use drugs, and skip classes were strong predictors of problem behaviour and weaker predictors of academic achievement. findings of this study were also corroborated by Zaki et.al. (2014) who stated in his study that student achievement is affected in many ways by the effects of a peer group.

\section{Conclusion}

Based on the findings of this study, the following conclusions were made:

1. There is significant relationship between peer pressure to overrule or disregard parental authority and poor academic performance among secondary school students in Cross River State, Nigeria.

2. There is significant relationship between peer pressure to alcoholism/drug addiction and poor academic performance among secondary school students in Cross River State, Nigeria.

\section{Recommendations}

Based on the findings of this study, the following recommendations are made: 
1. A lot of responsibility lies on parents to keep their wards under their (parents') control. This should be done from infancy (i.e. earliest childhood) of the child. A child should be trained and taught to appreciate parental authority. If necessary, strict disciplinary actions should be used by parents in an effort to carry this out. this requires adequate attention given by the parents to the child(ren). This is a continuous and long-term exercise which all parents should not shy from or delegate to someone else. A child who learns from childhood to appreciate parental authority would most likely continue to, and by so doing, build the right relationship with his/her parents, and is therefore at less risk of negative peer pressure.

2. While giving the child the best attention in training and teaching them how to live, the parent should specifically teach the child on the existence of negative peer pressure in schools and among adolescents. This prior information from the parents would have prepared the child for the possibility of being lured before the occurrence of the luring itself. This makes the child ready to respond appropriately when such pressures come from peers. The child would thus be immune from such negativities.

3. The above recommendations should be carried out also by guardians (in cases where the child is not their biological child) dutifully to their wards as though they (the children) are biologically their own. this attitude should also be adopted by counselors, teachers, and all those who are in position to provide some leadership to adolescents and secondary school students.

\section{References}

Arief, G. I \& Martin, AJ. (2011). Peer relationship and adolescents' academic and non-academics outcomes: samesex and opposite-sex peer effect and the role of school engagement. British journal of Educational psychology 81, 183-206.

Fuligni, A. J. (2007). Family obligation, college enrolment and emerging adulthood in Asian and Latin American families. Child Development Perspectives. Special Issue: Emerging Adulthood Around the World, 1(2), 96100.

Fuligni, A. J., Eccles, J. S., Barber, B. L., \&,Clements, P. (2001). Early Adolescent Peer Orientation and Adjustment During High School. Developmental Psychology 37(1), 28-36.

Fuligni, A.J., \& Pedersen, S. \{2002). Family obligation and the transition to young adulthood Developmental Psychology, 38, 856-868.

Hartney, $\quad$ E. (2011). What is pleasure? http://www.agrange.edu/responses/pdf/citatioris/nursing/adolescents\%20selresteem.pdf update July 5, 2011.

Izundu, I. T. (2005). Relationship between Home Environmental factors and academic performance of secondary school students. Unpublished

Jaiswal, S. K. \& Ckoudhuri, R. (2017). A-Review of the Relationship between Parental Involvement and Students' Academic Performance. The International Journal of Indian Psychology; Volume 4, Issue 3, No,99.

Jones, V. (2010). Stronger links: A guide to good practice for children's family-basedshort-term care service. Briston: Policy Press

Kathryn, D. (2010). Academic performance achievement. Retrieved June 14, 2011, from http://www.nichgy.org

Kelle B. Gormly, (2013). Peer pressure for students and adults can be positive. Pittsburgh Tribune Review

Nasreen, A. \& Naz, A. (2013). A Study of Factors Effecting Academic Achievement of Prospective Teachers. Journal of Soda/Science for Policy Implications, 7(1) pp. 23-31

Pandey, R.C. (2008). Academic achievement" as related to achievement motivation and parental background Indian psycho, 70 (4): 213-216).

Zaki, N. A Thabet, A. M, \& Hassan; A K. (2014) Effect of peer group and parents' socioeconomic status on Academic Achievement among " Preparatory Schools Students at assault city, AAMJ, VOL 12, NO (1) 